STUDI

FRANCESI

\section{Studi Francesi}

Rivista quadrimestrale fondata da Franco Simone

189 (LXIII | III) | 2019

Varia

\title{
Anne Reverseau, Le sens de la vue. Le regard photographique dans la poésie moderne
}

\section{Luigi Magno}

\section{(2) OpenEdition}

1 Journals

\section{Edizione digitale}

URL: https://journals.openedition.org/studifrancesi/21632

DOI: 10.4000/studifrancesi.21632

ISSN: 2421-5856

\section{Editore}

Rosenberg \& Sellier

\section{Edizione cartacea}

Data di pubblicazione: 1 décembre 2019

Paginazione: 604

ISSN: 0039-2944

\section{Notizia bibliografica digitale}

Luigi Magno, "Anne Reverseau, Le sens de la vue. Le regard photographique dans la poésie moderne»,

Studi Francesi [Online], 189 (LXIII | III) | 2019, online dal 01 mars 2020, consultato il 11 novembre 2021. URL: http://journals.openedition.org/studifrancesi/21632; DOI: https://doi.org/10.4000/studifrancesi. 21632

Questo documento è stato generato automaticamente il 11 novembre 2021.

\section{(c)}

Studi Francesi è distribuita con Licenza Creative Commons Attribuzione - Non commerciale - Non opere derivate 4.0 Internazionale. 


\title{
Anne Reverseau, Le sens de la vue. Le regard photographique dans la poésie moderne
}

\author{
Luigi Magno
}

\section{NOTIZIA}

Anne Reverseau, Le sens de la vue. Le regard photographique dans la poésie moderne, Paris, Sorbonne Université Presses, 2018, 520 pp.

1 La poesia modernista circola in Francia in un momento storico i cui limiti cronologici, assai labili, si posizionano tra l'inizio del xx secolo e il 1930 (a cavallo dunque tra le esperienze simboliste e quelle surrealiste), cioè in un arco temporale in cui il medium fotografico ha perso ormai ogni carattere di novità ma non è ancora percepito come una possibile forma d'arte. All'interno di questo particolare contesto e attraverso un lavoro articolato e ben documentato, che si inserisce a pieno titolo nell'ambito degli studi sulle interazioni tra il testo letterario e la fotografia, Anne Reverseau interroga le modalità con cui quest'ultima ha influenzato la poesia modernista francese. La fotografia costituisce in questo studio sia una sorta di filtro attraverso il quale riflettere sull'estetica modernista in poesia (di cui il libro propone una definizione nel quarto e ultimo capitolo), sia una focale che permette di ripensare parte del funzionamento stesso della poesia. A partire dalla vista - intesa sia come senso fisico che come immagine che deriva da una percezione sensoriale - la questione dello sguardo si trova proiettata al centro della riflessione poiché permette di fondere, inglobare e superare la dicotomia tra «vue» (sguardo e immagine di una realtà fisica) e «vision» (immaginario). L'analisi verifica dunque l'ipotesi dell'esistenza di un «regard photographique» quale risultante delle modifiche provocate dal dispositivo fotografico sul senso della vista e sul ruolo del visivo nella poesia modernista. 
2 Il rapporto tra i codici semiotici convocati nello studio pone non pochi problemi di ordine teorico e metodologico. Un taglio generalmente interdisciplinare delle analisi costituisce l'elemento in cui ha maturato la diversità dei metodi e dei criteri di studio e tutto il saggio si inserisce appieno nell'alveo della letteratura critica sulla nozione di dispositivo. Adottando l'idea di una «convergence esthétique» (A. Bazin) e evitando di proiettare in modo semplicistico la dimensione dell'immaginario fotografico in ambito stilistico (attraverso dunque il rifiuto di nozioni, come ad esempio quella di "stile fotografico", tanto impressionistiche quanto teoricamente di scarsa utilità), Anne Reverseau concentra così la sua riflessione sui modi in cui le «idées de la photographie» (la fotografia cioè intesa nel senso più ampio del termine) hanno sollecitato nei poeti nuovi modi di intendere la rappresentazione. La complessità dei rapporti tra il testo $\mathrm{e}$ la fotografia ha parimenti determinato un assetto tassonomico della metodologia adottata in cui, sulla scorta delle riflessioni di B. Vouilloux sulle forme in cui la scrittura declina la pittura, non mancano distinzioni formali del dialogo intermediale che oscilla tra integrazioni («intégrations»), raccordi («couplages»), prestiti («emprunts») e trasferimenti («transferts»).

3 Oltre a un'ampia introduzione e una conclusione, il saggio è strutturato in quattro capitoli. Nel primo, «Fabriquer, regarder et manipuler: pratiques et usages des poètes» (pp. 43-177), sono discussi, in una prospettiva storica e documentale, i fili che legano i poeti alle immagini fotografiche. Dapprima nel senso dell'utilizzo pratico e amatoriale della macchina fotografica da parti di molti di essi (Fargue, Mac Orlan, Albert-Birot, Segalen, Roussel), quindi degli usi che gli stessi hanno fatto delle immagini fotografiche - in una gamma di variazioni che oscilla dalla cattura allo sviluppo dell'immagine, dalla redazione di legende e la costruzione di una mitologia personale o collettiva (del poeta o dei poeti) al collezionismo. Il secondo capitolo, «Penser et rêver: imaginaires de la photographie» (pp. 179-284), esamina invece, con taglio tematico e descrittivo, la presenza diffusa della fotografia nei testi o, meglio, di quelli che Reverseau chiama gli immaginari del medium fotografico, cioè i modi in cui la fotografia, intesa come tecnica di registrazione e di diffusione, trova spazio nei testi poetici alimentando tensioni paradigmatiche che convocano di volta in volta statuto indiziale e posture documentali, oscillazioni temporali ed effetti ottici. Il terzo capitolo, «Reconfigurer le visuel: effets photographiques» (pp. 285-383), pone apertamente il problema teorico che attraversa tutto il libro e che interroga i modi in cui lo sguardo fotografico ridetermina, nella poesia modernista, l'idea della rappresentazione che si spinge così da un orizzonte mimetico («je vois cela») verso un piano deittico («je suis là»). Infine, come già accennato, l'ultimo capitolo, «Définir la modernité: un regard photographique» (pp. 385-466), mescolando l'approccio teorico con la riflessione estetica e filosofica, propone una ridefinizione della poesia modernista alla luce delle moderne teorie della fotografia. 